\title{
Comparative Proteomics Analysis of Mouse Habu Nephritis Models with and without Unilateral Nephrectomy
}

\author{
Lei Chen ${ }^{a, b}$ Yang Lu ${ }^{b} \quad$ Jun Wen ${ }^{b} \quad$ Xu Wang ${ }^{b}$ Lingling Wu ${ }^{b} \quad \mathrm{Di} \mathrm{Wu}^{\mathrm{b}}$ \\ Xuefeng Sun ${ }^{b}$ Bo Fu ${ }^{b}$ Zhong Yin ${ }^{b}$ Hongli Jiang ${ }^{a}$ Xiangmei Chen ${ }^{b}$
}

aDialysis Department of Nephrology Hospital, First Affiliated Hospital of Medicine School, Xi'an Jiaotong University, Xi'an, 'D Department of Nephrology, Chinese PLA General Hospital, Chinese PLA Institute of Nephrology, State Key Laboratory of Kidney Diseases, National Clinical Research Center for Kidney Diseases, Beijing, People's Republic of China

\section{Key Words}

Mesangial proliferative glomerulonephritis $\bullet$ Unilateral nephrectomy $\bullet$ Proteomics $\bullet$ Villin1 $\bullet$ Mesangial cell

\begin{abstract}
Background/Aims: Individuals possessing a single kidney are at greater risk of renal injury upon exposure to harmful stimuli. This study aimed to explore the pathogenesis of renal injury in glomerulonephritis with versus without unilateral nephrectomy (UNX). Methods: Histological analysis and label-free quantitative proteomics were performed on two models-the Habu snake venom-induced glomerulonephritis model with versus without UNX (HabuU and Habu models, respectively). The role of villin 1 , a differentially expressed protein (DEP) in mouse mesangial cells, was investigated. Results: Persistent mesangiolysis and focal hypercellularity together with reduced activation of cell proliferation in the HabuU model induced more serious renal injury compared with that in the Habu model. The DEPs between the two models were identified by label-free liquid chromatography-mass spectrometry. The KEGG pathway results indicated that regulation of actin cytoskeleton and focal adhesion were specifically enriched in the HabuU model. The cytoskeleton regulation protein villin 1 was downregulated in the HabuU model, but unchanged in the Habu model. Knockdown of villin 1 promoted apoptosis and inhibited the proliferation of mouse mesangial cells, suggesting villin 1 to be involved in glomerular lesion self-repair insufficiency. Conclusion: By assessing the proteomic profiles of the two models, this study identified several important differences, particularly villin 1 expression, in regulatory mechanisms between the two models. Our findings provide novel insight into the mechanism of serious renal injury in glomerulonephritis with UNX.
\end{abstract}

Xiangmei Chen, MD

and Hongli Jiang, Ph. D

KARGER
Dept Nephrol, Chinese PLA General Hospital, Chinese PLA Institute of Nephrology, State Key Laboratory of Kidney Diseases, National Clinical Research Center for Kidney Diseases, Fuxing Road 28, Beijing 100853, (PR China); Dialysis Dept of Nephrology Hospital, First Affiliated Hospital of Medicine School, Xi'an Jiaotong University, Xi'an 710061, Shaanxi (China); E-Mail xmchen301@126.com/j92106@sina.com 


\section{Cellular Physiology Cell Physiol Biochem 2016;39:1761-1776 \\ \begin{tabular}{ll|l} 
and Biochemistry Published online: October 17, 2016 & $\begin{array}{l}\text { () 2016 The Author(s). Published by S. Karger AG, Basel } \\
\text { www.karger.com/cpb }\end{array}$ \\
\hline
\end{tabular} \\ Chen et al.: Proteomics Analysis of Habu Nephritis with Versus without UNX}

\section{Introduction}

Individuals may possess a single kidney as a result of various physiological and pathological conditions, such as congenital solitary kidney, obstruction of the unilateral urinary tract with renal insufficiency, kidney donation, and surgical unilateral nephrectomy for tumors. Structural and functional changes in the remaining kidney are important concerns for nephrologists. The remaining kidney frequently shows compensatory hypertrophy to satisfy the increased workload and maintain normal kidney function by means of hyperfiltration [1]. Individuals (both humans and animals) with a single kidney show few pathological signs in the remaining kidney under normal conditions [2, 3]. However, the remaining kidney is at greater risk of glomerular disease upon exposure to harmful stimuli. Rayner et al. [4] reported that consuming cholesterol following unilateral nephrectomy led to glomerular hypertrophy and glomerulosclerosis in rats. Chagnac et al. [5] showed that unilateral nephrectomy (UNX), a surgical procedure used to remove a contralateral kidney, with adriamycin nephrosis worsened interstitial nephrosis and aggravated the formation of tubular cysts in rats. Zheng et al. [6] demonstrated that UNX accelerated the progression of diabetic nephropathy (DN) in diabetic OVE26 mice. Since UNX provides an effective means of understanding the biology and the progression of renal disease in the remaining kidney, it is widely used in animal models of kidney diseases, such as DN, acute kidney injury, and glomerular sclerosis [7-11].

Mesangial proliferative glomerulonephritis (MesGN) is the most common type of glomerulonephritis in China and is characterized by mesangial cell proliferation accompanied by mesangial matrix expansion [12]. MesGN may involve cell proliferation, apoptosis and immune imbalance [13]. Anti-Thy1 antibody-induced glomerulonephritis in rats and Habu snake venom (HSV)-induced glomerulonephritis in mice are the classical experimental models exhibiting glomerular lesions similar to those of human MesGN [14, 15]. Glomerular lesions induced by a single injection of anti-Thy1 antibody or HSV are reversed after $\sim 1$ month $[15,16]$. However, other studies indicated that injection of anti-Thy1 antibody or HSV after UNX led to more severe damage and irreversible glomerular sclerosis $[17,18]$. The above results suggested that UNX enhances progressive renal insufficiency, but the underlying mechanism is unclear.

In this study, we generated an HSV-induced glomerulonephritis model in both normal and UNX mice. The clinical features and cell proliferation and apoptosis were examined and analyzed. Moreover, a proteomics method was used to screen differentially expressed proteins (DEPs). The altered expression of some proteins was suggestive of the mechanism underlying the changes following unilateral nephrectomy. By comparing the proteomic profiles of the Habu nephritis model (Habu model) and the Habu nephritis model with UNX (HabuU model), this study aimed to identify important differences at the molecular level in the regulatory mechanisms underlying progressive renal disease following unilateral nephrectomy, which may facilitate the development of novel therapeutic strategies for patients possessing a single kidney.

\section{Methods and Materials}

Induction of glomerulonephritis

Glomerular lesions were induced in 72 male C57BL/6 mice (18-20 g) (Aberford Experimental Animal Technology Co., Beijing, China), of which 36 were unilaterally nephrectomized. One week later, 24 normal mice and 24 UNX mice were injected intravenously in the tail vein with HSV (Trimeresurus flavoviridis; 2.5 $\mathrm{mg} / \mathrm{kg}$ body weight; Wako Pure Chemical Industries, Osaka, Japan) to generate the Habu model and the Habu with UNX model (HabuU model). The remaining 12 UNX mice and 12 normal mice were injected with an equal volume of PBS through the tail vein as controls. The controls were sacrificed immediately (day 0), while the others were subdivided and sacrificed at day 7 ( $n=12$ for the HabuU model, $n=12$ for the Habu model) and day 14 (n=12 for the HabuU model, n=12 for the Habu model) after HSV injection. Renal 


\section{Cellular Physiology Cell Physiol Biochem 2016;39:1761-1776 \begin{tabular}{l|l|l}
\hline DOI: 10.1159/000447876 & (c) 2016 The Author(s). Published by S. Karger AG, Basel
\end{tabular} and Biochemistry Published online: October 17, 2016 www.karger.com/cpb \\ Chen et al:: Proteomics Analysis of Habu Nephritis with Versus without UNX}

cortex slices were obtained and fixed in $10 \%$ buffered formalin for histological and immunohistochemistry assessment. Glomeruli were isolated by the differential-sieving method from the left part of the renal cortex. Briefly, the renal cortex was minced using scissors and filtered through 140-, 75- and 53- $\mu \mathrm{m}$ sieves. Glomeruli obtained from the 53- $\mu \mathrm{m}$ sieve were harvested, with $\sim 80 \%$ purity, for proteomic and Western blot analyses. Cardiac puncture was used for collection of blood samples.

All animals were well bred and colonies maintained at $25{ }^{\circ} \mathrm{C}$ under a $12: 12 \mathrm{~h}$ light: dark cycle. They were provided ad libitum access to water and a standard diet (Aberford Experimental Animal Technology Co., Beijing, China) for the duration of the study.

Animal welfare and experimental procedures were carried out in strict accordance with the Guide for the Care and Use of Laboratory Animals (U.S. National Research Council, 1996).

\section{Histological examination}

The fixed renal cortex tissues were embedded in paraffin for histological examination. Each paraffin section was cut into $4-\mu \mathrm{m}$-thick slices and subjected to periodic acid-Schiff staining. Glomerular lesions were evaluated by light microscopy. The glomerular nucleated cell numbers were determined in thirty randomly selected glomeruli from the renal cortex of each mouse. To quantify glomerular mesangiolysis, capillary widening was scored as the mesangiolysis index. As described previously [16], a score of 0-4 was applied: 0 , no capillary widening in the glomerular tuft; 1 , capillary widening involving up to $25 \%$ of the glomerular tuft; 2, capillary widening of $25-50 \%$; 3 , capillary widening of 50-75\%; 4, capillary widening involving more than $75 \%$ of the glomerular tuft. The mesangial hypercellularity index was used to assess the severity of hypercellular lesions as follows: 0 , no hypercellularity, with fewer than three cells per mesangial area; 1 , focal mild hypercellularity, $<50 \%$ of glomeruli with three to five cells per mesangial area; 2 , diffuse mild hypercellularity or focal segmental prominent hypercellularity, the latter with more than five cells per mesangial area; and 3, diffuse global prominent hypercellularity [19]. Thirty randomly selected glomeruli from the renal cortex of each mouse were scored.

\section{Cell proliferation assay}

Proliferating cell nuclear antigen (PCNA) immunohistochemical assessment was performed to assess cell proliferation. Deparaffinized paraffin sections $(4 \mu \mathrm{m})$ were reacted with $3 \%$ hydrogen peroxide for 10 min at room temperature to block endogenous peroxidase activity. The microwave antigen repair technique was applied prior to incubation of the sections with a mouse polyclonal antibody against PCNA (1:500, Abcam, Cambridge, UK) overnight at $4{ }^{\circ} \mathrm{C}$. Then, the sections were reacted with a biotinylated secondary antibody at room temperature for $1 \mathrm{~h}$ and incubated with an avidin-biotinylated horseradish peroxidase (Vecta-Stain Elite ABC Kit (Vector Laboratories, Burlingame, CA, USA) for 40 min at room temperature. The Vecta-stain DAB Kit (Vector Laboratories, Burlingame, CA, USA) was used as the chromogen, and slides were counterstained with hematoxylin. The PCNA-positive rate was calculated as the number of positive cells relative to the number of total glomerular cells (five mice were assessed per group, and 30 glomeruli were counted per mouse).

\section{Cell apoptosis assay}

4',6-diamidino-2-phenylindole (DAPI) staining of paraffin sections was conducted to visualize apoptotic cells in glomeruli. Deparaffinized paraffin sections $(4 \mu \mathrm{m})$ were reacted with DAPI (Abcam) for 5 min at room temperature, protected from light. Cells with condensed nuclei were visualized by fluorescence microscopy. The percentage of cells with condensed nuclei in each glomerulus was calculated to determine the extent of apoptosis (five mice were assessed per group, and 30 glomeruli were counted per mouse).

\section{Label-free quantitative proteomics}

Equal quantities of glomerular protein from 12 mice in each group were subjected to liquid chromatography mass spectrometry (LC-MS). Proteins $(50 \mu \mathrm{g})$ were separated by $12 \%$ SDS-PAGE, and each lane of the gel was cut into seven fragments, which were digested with trypsin. Two-dimensional (2D) LC-MS (XEVO QTOF, Waters Corp., Manchester, UK) was used to analyze the peptides. Samples were separated on a $180 \mu \mathrm{m} \times 50 \mathrm{~mm}$ Symmetry C18 $5 \mu \mathrm{m}$ (Waters Corp., Manchester, UK) reversed-phase trap column in the first dimension using solvent A (200 mM ammonium formate, $\mathrm{pH}$ 10.0) and solvent B $(\mathrm{CH} 3 \mathrm{CN})$. We used three solvent plugs set automatically by Masslynx 4.1 to elute the fractions sequentially. 


\section{Cellular Physiology Cell Physiol Biochem 2016;39:1761-1776 \begin{tabular}{l|l|l}
\hline DOI: 10.1159/000447876 & (c) 2016 The Author(s). Published by S. Karger AG, Basel
\end{tabular} and Biochemistry Published online: October 17, 2016 www.karger.com/cpb \\ Chen et al.: Proteomics Analysis of Habu Nephritis with Versus without UNX}

In the second dimension, peptides were eluted using a nanoACQUITY system equipped with a C18 column (75 $\mu \mathrm{m} \times 100 \mathrm{~mm}$; Waters Corp.) with solvent A (water) and solvent B (CH3CN). The procedure and data analysis were similar to those in our previous study [20]. The column temperature was controlled at $35^{\circ} \mathrm{C}$. Two-hundred femtomoles per microliter of [Glu1] fibrinopeptide B were applied as the lock mass, with a constant flow rate of $300 \mathrm{~nL} / \mathrm{min}$. Each sample was detected in triplicate. The elevated-energy (MSE) method was applied. The spectral acquisition time in each mode was $0.6 \mathrm{~s}$. In the low-energy MS mode, data were collected at a constant collision energy of $6 \mathrm{eV}$. In the elevated-energy MS mode, the collision energy was increased from 15 to $36 \mathrm{eV}$. Each sample group contained three replicates, which were combined for the analysis of the expression profiles by PLGS 2.4. The precursor and fragment ion tolerance were determined automatically. The default protein identification criteria included a maximal protein mass of 500,000 Da and detection of at least three fragment ions per peptide, seven fragment ions per protein. We selected fixed modification of carbamidomethyl- $\mathrm{C}$ and the detected variable modifications, including acetylation (N-terminus), deamidation $(\mathrm{N} / \mathrm{Q}$ ) and oxidation of methionines. At most, two missed cleavages and a false positive rate of $4 \%$ were allowed. Normalization was performed using the auto-normalization function [21], which exhibited an effect similar to the internal standard [22]. The NCBI mouse database (released in March 2012) was used as the reference database. Only high-confidence proteins (OK $=2)$ were retained for further analysis. Only those proteins quantified in at least two replicates or identified exclusively in one group and at least two replicates were selected. The statistical analysis was carried out using PLGS 2.4, and only those proteins demonstrating fold changes $>1.5$ with p-values $<0.05$ were considered DEPs.

\section{Bioinformatics analysis}

DAVID Bioinformatics Resources 6.7 was used for Kyoto Encyclopedia of Genes and Genomes (KEGG) pathway enrichment analyses. The DEPs at each time point in the Habu model or HabuU model were enriched in different biological pathways. An EASE score (a modified Fisher's exact test) $<0.1$ and p-value $<0.05$ after Benjamin-Hochberg correction were the criteria for significantly enriched biological pathways.

\section{Western blot analysis}

Protein levels were determined by Western blot analysis. Proteins $(30-60 \mu \mathrm{g})$ were separated on a $12 \%$ SDS-PAGE gel and transferred to a nitrocellulose membrane. After blocking with 3\% bovine serum albumin (Invitrogen, Carlsbad, CA, USA), the membrane was incubated with primary antibodies overnight at $4{ }^{\circ} \mathrm{C}$. Then, unbound primary antibody was removed, and the sections were rinsed in Tris-buffered saline containing Tween. The membrane was incubated with secondary antibodies for $1 \mathrm{~h}$ at room temperature. The blots were developed using ECL reagent (Santa Cruz Biotechnology, Inc., Dallas, TX, USA) according to the manufacturer's instructions. Images were acquired using an Opti-Chemi 600 (UVP, Upland, CA, USA). We determined the levels of FHL2, SEPT2 (Santa Cruz Biotechnology, Inc.), activated caspase 3, p21 (Abcam), Bax, p27 (Cell Signaling Technology, Danvers, MA, USA) and villin 1 (VIL1) (Proteintech Group, USA). $\beta$-actin (Sigma-Aldrich, St. Louis, MO, USA) was used as a control. Image J software was used for blot analysis. The intensities of the protein bands are presented as ratios to that of $\beta$-actin, and data from the NC group were arbitrarily set as 1.0 .

\section{Mouse mesangial cell (MMC) culture and cell transfection}

MMCs (ATCC, USA) were maintained in RMPI 1640 medium (Corning Inc., Corning, NY, USA) with 5\% fetal bovine serum (Invitrogen). siRNA transfection was conducted in MMCs to knock down the expression of VIL1. MMCs transfected with nonsense siRNA were used as the negative control group (NC group). In case of off-target effects, two different VIL1 siRNA sequences were used in this study. We transfected $3 \times 10^{5}$ cells per six-well plate with siRNA (80 $\mathrm{nM}$ ) using Lipofectamine ${ }^{\mathrm{TM}}$ RNAi MAX transfection reagent (Invitrogen) according to the manufacturer's instructions for reverse transfection. The following target sequences were used:

\section{NC siRNA: 5'-UUCUCCGAACGUGUCACGU-3'}

VIL1 SIRNA-1: 5'-CCTCGATGGAAGTAATAAA-3;

VIL1 SiRNA-2: 5' -CCTCACCTCATGTCTATCT-3'.

The siRNA sequences were designed and produced by GenePharma Co., Ltd., Shanghai, China. The transfection efficiency was determined using a florescence microscope. At $48 \mathrm{~h}$ post-transfection, cells were terminated and prepared for subsequent assays. 


\section{Cellular Physiology Cell Physiol Biochem 2016;39:1761-1776 \begin{tabular}{l|l|l}
\cline { 2 - 2 } DOI: 10.1159/000447876 & (c) 2016 The Author(s). Published by S. Karger AG, Basel
\end{tabular} and Biochemistry Published online: October 17, 2016 www.karger.com/cpb \\ Chen et al.: Proteomics Analysis of Habu Nephritis with Versus without UNX}

Total cell number counts

At $48 \mathrm{~h}$ after siRNA transfection, cells were trypsinized and enumerated using a hemocytometer. Briefly, a drop was placed on the hemocytometer and observed under a microscope. The cells in four sets of 16 corner squares of the hemocytometer were counted. Next, the average cell count from each set of 16 squares was multiplied by $10^{4}$ to calculate the number of viable cells $/ \mathrm{mL}$. The total number of cells was estimated as the total volume of cell suspension $\times$ the number of viable cells $/ \mathrm{mL}$. Cell numbers were expressed as fold changes relative to that of the NC group, which was normalized to 1 . The assay was performed in at least triplicate.

Hoechst 33342 apoptosis assay

To detect apoptosis, cells were treated with $10 \mu \mathrm{g} / \mathrm{mL}$ Hoechst 33342 for $10 \mathrm{~min}$ at $37 \mathrm{C}$. Cells with condensed nuclei were observed by fluorescence microscopy and counted in at least five fields per plate. The percentage of cells with condensed nuclei among the total number of cells was calculated to determine the extent of apoptosis. The assay was performed in at least triplicate.

EdU (5-ethynyl-2'-deoxyuridine) incorporation proliferation assay

To investigate the effect of VIL1 siRNA on mesangial cell proliferation, we performed an EdU incorporation assay using the Click-iT® EdU Alexa Fluor ${ }^{\circledR} 555$ Imaging Kit (Invitrogen). All procedures were conducted according to the manufacturer's instructions. Briefly, transfected MMCs were incubated with $10 \mu \mathrm{M}$ EdU/well for $4 \mathrm{~h}$ and then fixed and permeabilized. The Click-iT® reaction cocktail was used to stain EdU-positive nuclei and DAPI to stain all nuclei. The cells were visualized by fluorescence microscopy. The percentage of EdU-positive nuclei to total nuclei was calculated as the proliferation rate in three random fields per well. The assay was performed in at least triplicate.

\section{Statistical analysis}

Statistical analysis was performed using SPSS version 20.0. Charts were generated using GraphPad Prism version 6.0. Data are expressed as means \pm SD. Statistical significance (a significant difference was defined as $\mathrm{p}<0.05$ and a predominant significant difference as $\mathrm{p}<0.01$ ) was evaluated by two-way ANOVA followed by Tukey's honestly significant difference (HSD) test for post hoc analysis. All relative units were expressed as fold changes compared with the relevant control group, which was normalized to 1.0.

\section{Results}

Co-existence of persistent mesangiolysis and focal hypercellularity contributed to deteriorated kidney function in the HabuU model compared with the Habu model at days 7 and 14 after HSV injection

PAS staining was performed to assess the severity of glomerular lesions. In the Habu model, diffuse hypercellularity and mesangial matrix accumulation peaked at day 7 and decreased subsequently by day 14 after HSV injection. Notably, mesangiolysis was not observed at days 7 and 14 in the Habu model. In contrast, several mesangiolytic lesions were found in the HabuU model at days 7 and 14. Although several hypercellular lesions were observed at days 7 and 14 in the HabuU model, the majority showed focal hypercellularity, which was considerably milder than that in the Habu model. The number of cells was markedly lower at days 7 and 14 in the HabuU model compared with the Habu model (Fig. 1 A). According to semi-quantitative analysis, the mesangiolysis index was significantly higher and the hypercellularity index significantly lower in the HabuU model than in the Habu model (Fig.1B C) We next determined renal function damage by examining serum creatinine and blood urea nitrogen levels. The serum creatinine levels were notably higher at both days 7 and 14 in the HabuU model than in the Habu model (Fig. 1 D). The blood urea nitrogen level was markedly higher at day 7 in the HabuU model than in the Habu model (Fig. 1 E). However, the blood urea nitrogen level was slightly higher at day 14 in the HabuU model than in the Habu model, albeit not significantly so $(14.28 \pm 1.65 \mathrm{mmol} / \mathrm{L}$ vs. $22.1 \pm$ $9.93 \mathrm{mmol} / \mathrm{L}, \mathrm{p}=0.301)$. Histopathological changes, including persistent mesangiolysis and milder hypercellularity compared with Habu nephritis without UNX, resulted in damage 


\section{Cellular Physiology Cell Physiol Biochem 2016;39:1761-1776 \begin{tabular}{l|l|l}
\hline DOI: 10.1159/000447876 & ( ) 2016 The Author(s). Published by S. Karger AG, Basel
\end{tabular}

Fig. 1. Clinical features of the two models. (A) Periodic acid-Schiff (PAS) staining of renal tissues obtained at the indicated days after HSV injection and glomerular nucleated cell counts in the two models $(n=5$ per group and 30 glomeruli per mouse, me$\mathrm{an} \pm S D$ ). (B) The mesangiolysis index of renal tissues obtained at the indicated days in the two models. $(n=5$ per group and 30 glomeruli per mouse, mean \pm SD) (C) The hypercellularity index of renal tissues obtained at the indicated days in the two models. ( $n=5$ per group and 30 glomeruli per mouse, mean \pm SD). (D) Blood urea nitrogen levels in the two models ( $n=6$ per group, mean \pm SD). (E) Serum creatinine levels in the two models ( $n=6$ per group, mean \pm SD). *Significant difference $(p<0.05)$ between the Habu and HabuU models. ${ }^{* *}$ Predominant significant difference $(p<0.01)$ between the Habu and HabuU models.

to glomerular structures, which contributed to serious deterioration of kidney function in Habu nephritis with UNX.

Activation of apoptosis and reduced activation of proliferation were associated with persistent mesangiolysis and focal hypercellularity at days 7 and 14 in the HabuU model compared with the Habu model

Cell proliferation and apoptosis are the primary development and recovery mechanisms of mesangial proliferation in Habu nephritis. In this study, cell proliferation and apoptosis in glomerular lesions were determined by PCNA immunohistochemistry and DAPI staining, respectively. PCNA staining results showed that the cell proliferation rate was markedly lower at days 7 and 14 in the HabuU model than in the Habu model (Fig. 2 A) However, apoptosis rates were similar between the two models at days 7 and 14 (Fig. 2 B). The activation of cell proliferation at day 7 in the Habu model promoted the recovery of mesangiolysis at the pre-stage (from days 1 to 3 ) and activation of cell apoptosis at day 14, thereby reducing the number of over-proliferative cells. However, in the HabuU model, due to reduced activation of proliferation, apoptosis inhibited the recovery of mesangiolysis at days 7 and 14, which may result in deteriorated kidney function.

The common and unique KEGG pathways in the HabuU model compared with the Habu model

To explore the differential mechanisms of regulation in the two models, label-free quantitative proteomics was performed. In the Habu model, 167 DEPs (68 downregulated 


\section{Cellular Physiology Cell Physiol Biochem 2016;39:1761-1776

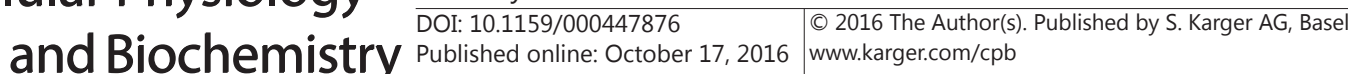

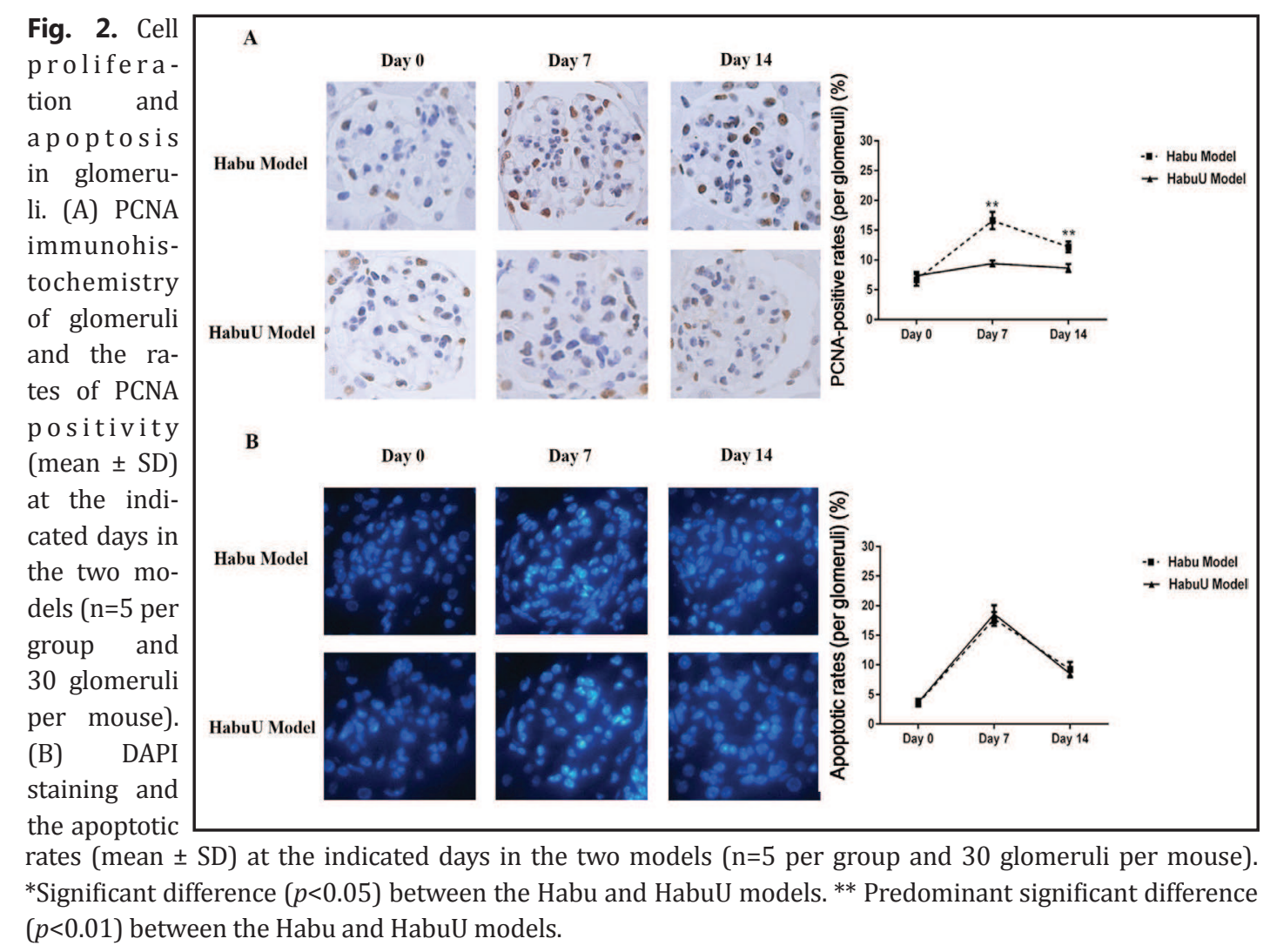

and 99 upregulated) were identified at day 7 and 262 DEPs (108 downregulated and 154 upregulated) at day 14. In the HabuU model, 169 DEPs (122 downregulated and 47 upregulated) were identified at day 7 and 134 DEPs (38 downregulated and 96 upregulated) at day 14. (Fig. 3)

KEGG pathway enrichment analysis was performed to explore the mechanism of regulation. First, the pathways in the Habu model (Fig. 4 A, B) and the HabuU model (Fig. 4 C, D) at days 7 and 14 were explored. Then, these pathways were compared to identify those common versus unique to the two models (Fig. 4 E). We focused on the pathways that were enriched at both days 7 and 14 in each model. These pathways were considered activated during the entire process of nephritis, which plays a crucial role in disease progression. Three common signaling pathways - glycolysis/gluconeogenesis, the citrate cycle (tricarboxylic acid cycle), and valine, leucine and isoleucine degradation-were detected in the two models at days 7 and 14 (Fig. 4 E). These pathways are associated with regulation of energy metabolism during nephritis. However, the majority of DEPs involved in these pathways differed significantly in expression between the two models (Fig. 5) (Table 1). For example, in the glycolysis/gluconeogenesis pathway, ENO1, ENO2 and ENO3 were downregulated at day 7 in the Habu model, whereas they were upregulated at days 7 and 14 in the HabuU model. Therefore, these shared pathways exerted differential effects in the two models.

The pathways enriched at both days 7 and 14 that were unique to each model were identified (Fig. 4E, 5). In the Habu model, four pathways, biosynthesis of unsaturated fatty acids, butanoate metabolism, lysine degradation and tryptophan metabolism, were enriched at days 7 and 14. In the HabuU model, regulation of actin cytoskeleton and focal adhesion were enriched at days 7 and 14. These independent pathways may mediate the diverse pathological changes observed in the two models. For example, disturbed regulation of the actin cytoskeleton, seen in the HabuU model, is closely related to cell activities such as apoptosis and growth. Therefore, the role of the cytoskeleton protein VIL1 in Habu nephritis progression after unilateral nephrectomy was evaluated. 


\section{Cellular Physiology Cell Physiol Biochem 2016;39:1761-1776

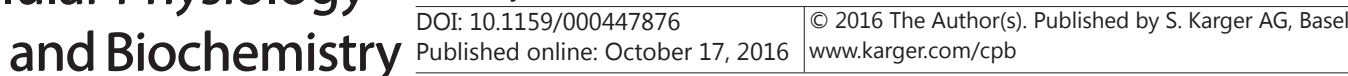

Fig. 3. Classification of DEPs into five clusters according to their expression patterns. (A) DEPs downregulated at days 7 and 14 in the Habu model.

(B) DEPs upregulated only at day 14 in the Habu model. (C) DEPs upregulated at days 7 and 14 in the Habu model. (D) DEPs downregulated only at day 14 in the Habu model. (E) DEPs downregulated at days 7 and 14 in the HabuU model. (F) DEPs upregulated only at day 14 in the HabuU model. (G) DEPs upregulated at days 7 and 14 in the HabuU model. (H) DEPs downregulated only at day 7 in the HabuU model.
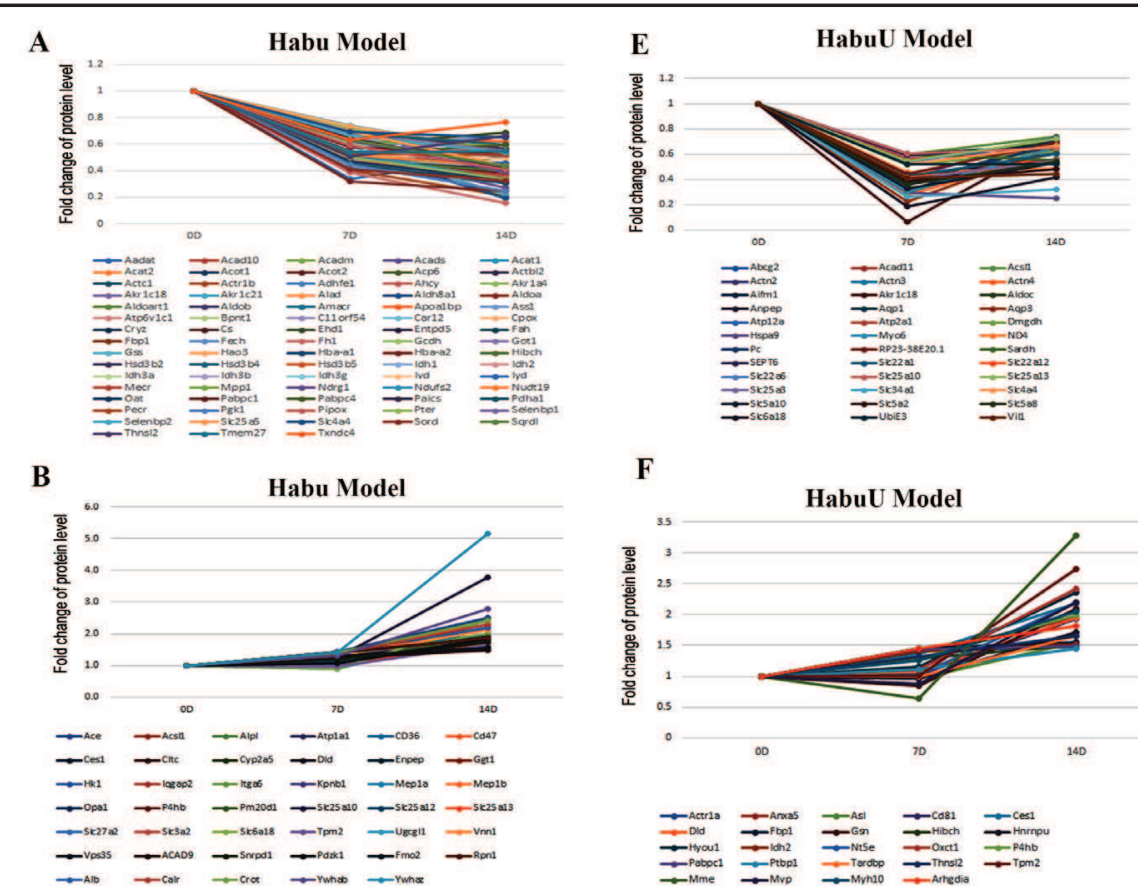

F HabuU Model
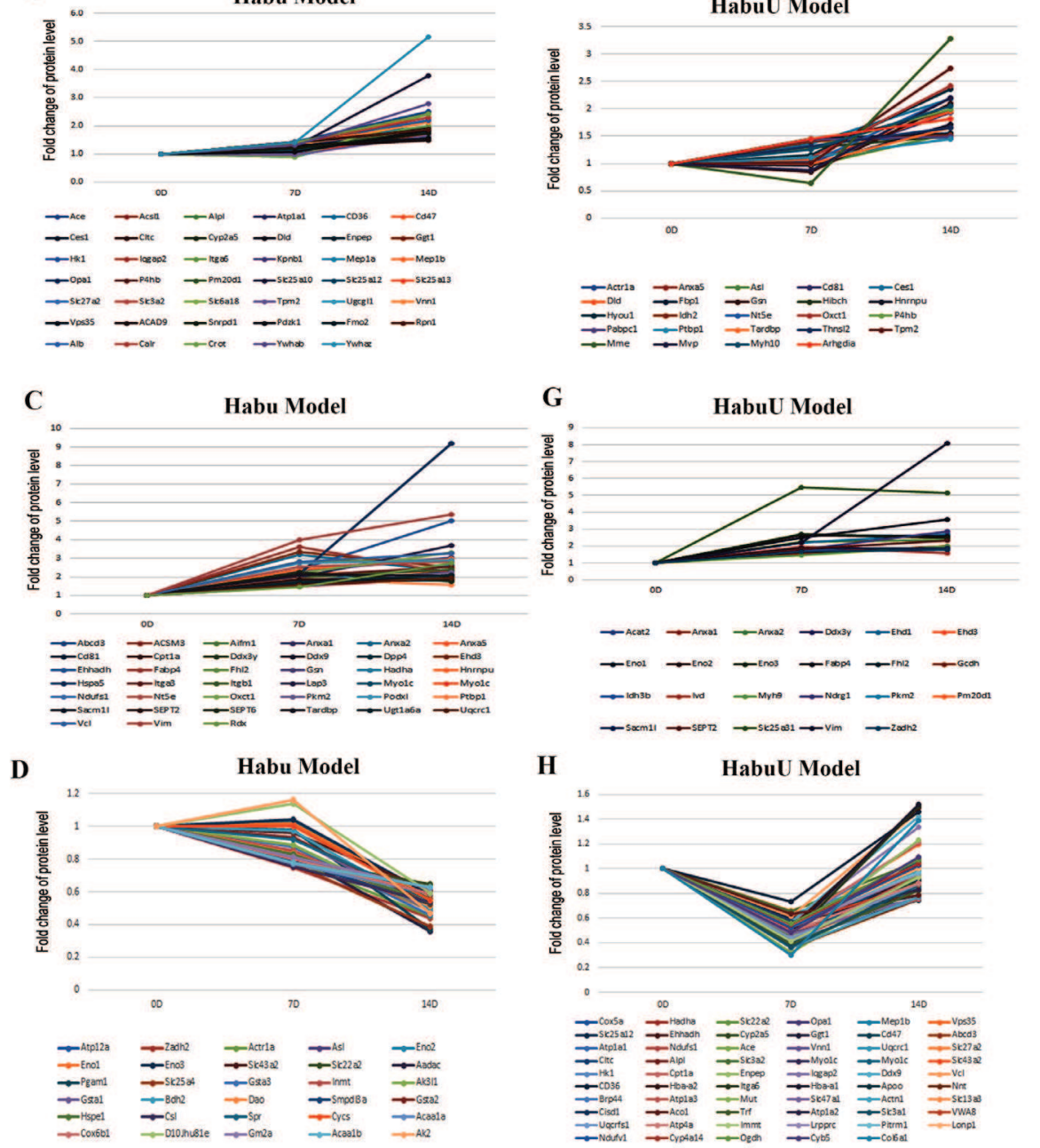

Low expression of VIL1 inhibited proliferation and promoted apoptosis of MMCs, which was associated with renal lesions at day 7 in the HabuU model

First, several DEPs (VIL1, SEPT2 and FHL2) were validated by Western blotting (Fig. 6 A). SEPT2 and FHL2 were upregulated at days 7 and 14 in both models, which was consistent with the LC-MS results. However, the expression of VIL1 was downregulated at days 7 and 14 in the HabuU model but downregulated only at day 14 in the Habu model. (VIL1 was found to be unchanged by LC-MS but to be downregulated by Western blotting at day 14 in the Habu model). VIL1 has important functions in regulating actin dynamics, cell morphology, the 


\section{Cellular Physiology Cell Physiol Biochem 2016;39:1761-1776 \begin{tabular}{ll|l} 
and Biochemistry & Published online: October 17, 2016 & $\begin{array}{l}\text { ( ) 2016 The Author(s). Published by S. Karger AG, Basel } \\
\text { www.karger.com/cpb }\end{array}$
\end{tabular}}

Chen et al.: Proteomics Analysis of Habu Nephritis with Versus without UNX

Fig. 4. KEGG pathway enrichment analysis. selected using an EASE score $>0.1$ and a p-value $<0.05$ after Benjamin-Hochberg correction) (A) The pathways enriched among the DEPs in the Habu model at day 7. (B) The pathways enriched among the DEPs in the HabuU model at day 7. (C) The pathways enriched among the DEPs in the Habu model at day 14. (D) The pathways enriched among the DEPs in the HabuU model at day 7. (E) Comparison of pathways between the two models. (Pathways were

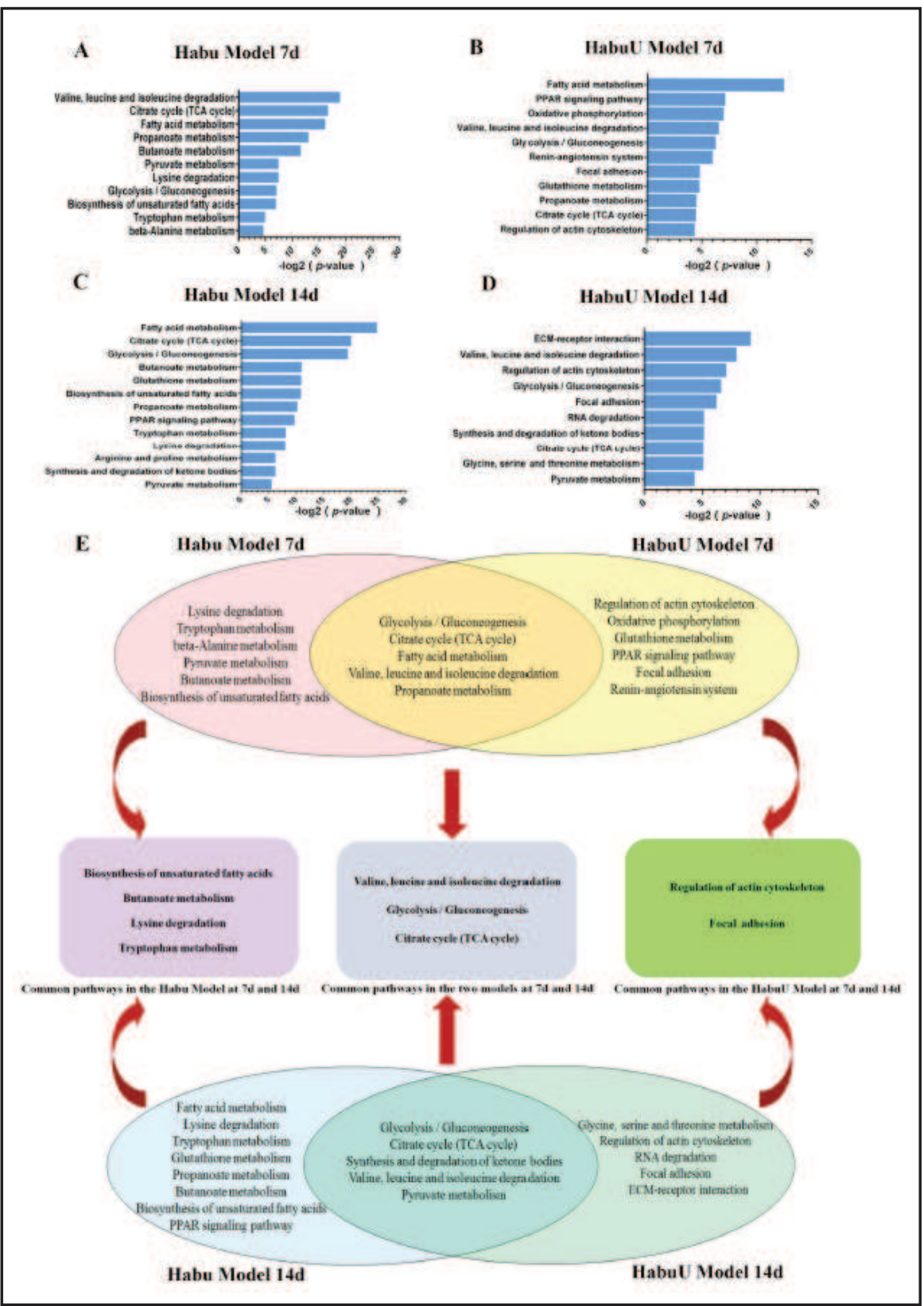

epithelial-to-mesenchymal transition, and cell survival [23-26]. Although VIL was reported [27] to be expressed predominantly in proximal tubular cells, in this study its expression level was comparable between mesangial cells and proximal tubular cells (Fig. 7). Therefore, the downregulation of VIL1 at day 7 in the HabuU model may be related to inhibition of mesangial cell proliferation and promotion of apoptosis. We generated VIL1-knockdown models by siRNA transfection in MMCs to explore the role of VIL1 in apoptosis and proliferation of mesangial cells. In the case of off-target effects, two sequences of VIL1 siRNA were used in this study. After $48 \mathrm{~h}$ of transfection, the total cell number decreased significantly in both VIL1 siRNA-transfection groups (VIL1 siRNA-1 and VIL1 siRNA-2) compared with the NC group (Fig. 6 B). The rate of apoptosis was higher in the two siVIL1 transfection groups compared with the NC group (Fig. 6 C). Moreover, the EDU assay indicated fewer proliferating cells in the two VIL1 siRNA transfection groups than in the NC group (Fig. 6 D). Western blotting results showed that $\mathrm{p} 21, \mathrm{p} 27$, Bax and caspase 3 expression was significantly upregulated in the VIL1-knockdown groups (Fig. 6 E). These results confirmed that low expression of VIL1 


\section{Cellular Physiology Cell Physiol Biochem 2016;39:1761-1776 \begin{tabular}{ll|l} 
and Biochemistry & Published online: October 17, 2016 & $\begin{array}{l}\text { ( ) 2016 The Author(s). Published by S. Karger AG, Basel } \\
\text { www.karger.com/cpb }\end{array}$
\end{tabular} \\ Chen et al.: Proteomics Analysis of Habu Nephritis with Versus without UNX}

Fig. 5. The expression patterns of DEPs in the three pathways shared by the two models and the two pathways unique to the HabuU model. The timeframe from days 0 to 7 comprised the DEPs changed at day 7 , that from days 0 to 14 comprised the DEPs changed at days 7 and 14, and the timeframe from days 7 to 14 comprised the DEPs changed at day 14 (red, upregulated and blue, downregulated).

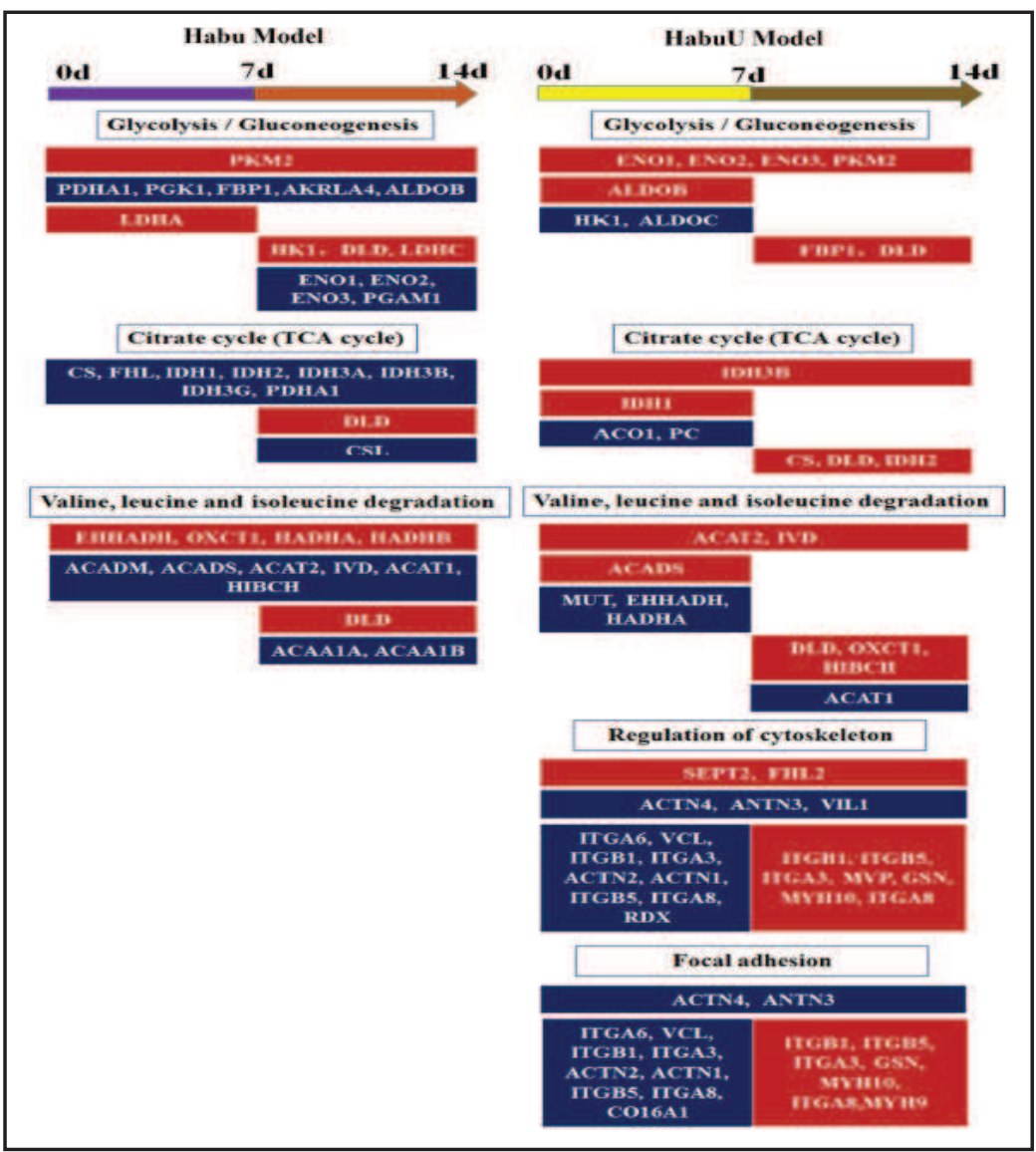

inhibited mesangial cell proliferation and promoted their apoptosis, which were associated with the suppression of mesangiolysis repair at day 7 in the HabuU model.

\section{Discussion}

In this study, Habu nephritis and HabuU nephritis models were developed, and their mechanisms of pathogenesis explored by proteomics. At day 1 after HSV injection, the two models showed glomerular lesions of similar severity, which suggested that the HSV toxin itself did not influence the initial kidney injury in the two models (Fig. 8). However, the HabuU model showed more severe renal injury, as indicated by higher levels of serum creatinine and blood urea nitrogen, compared with the Habu model at days 7 and 14, which was related to its specific pathological progress of recovery from toxin injury. In the Habu model, mesangiolysis was detected by day 3 , diffuse hypercellularity by day 7 and partial recovery by day 14 , in agreement with previous reports $[28,29]$. In contrast, focal hypercellularity, accompanied by partial mesangiolysis, from days 7 to 14 was the major feature of the HabuU model, which differed from that of the Habu model. Therefore, the differences in pathological progress promoted more serious renal injury in the HabuU model.

The pathological progression of mesangial proliferative nephritis is due to disturbances in cell proliferation and apoptosis [16, 30,31]. In the Habu model, we found that activated cell proliferation (an increase in the rate of PCNA positivity) promoted repair of the mesangiolysis induced by immunity and remodeling of glomerular structure at day 7 . However, in the HabuU model, mesangial cell apoptosis was activated and proliferation was less activated than that in the Habu model at day 7, which partially suppressed the repair of mesangiolysis. Therefore, the lack of recovery of mesangiolysis aggravated renal function damage in the HabuU model [32]. 


\section{Cellular Physiology Cell Physiol Biochem 2016;39:1761-1776 \begin{tabular}{ll|l} 
and Biochemistry & DOI: 10.1159/000447876 & $\begin{array}{l}\text { O 2016 The Author(s). Published by S. Karger AG, Basel } \\
\text { www.karger.com/cpb }\end{array}$ \\
\cline { 2 - 3 }
\end{tabular} Chen et al.: Proteomics Analysis of Habu Nephritis with Versus without UNX}

To explore the molecular mechanisms in the two models, a proteomics analysis of glomeruli was performed. Based on KEGG pathway analysis, three common pathways-glycolysis/gluconeogenesis, the citrate cycle (TCA cycle), and valine, leucine and isoleucine degradation-were identified in the two models. These pathways regulated energy metabolism during the entire process in both models. The disturbance of glycolysis and valine, leucine and isoleucine degradation may interfere with the TCA cycle, which altered cellular ATP production in the Habu and HabuU models. Abnormal energy metabolism can affect cell activities $[33,34]$. However, the DEPs involved in these pathways were different between the two models, which suggests different effects on cell activities.

The pathways unique to each model were also identified. In the Habu model, aberrant fatty acid metabolism (biosynthesis of unsaturated fatty acids and butanoate metabolism) may be involved in cell proliferation and apoptosis by affecting ATP generation. In the HabuU model, disturbed cytoskeleton regulation may contribute to activation of cell apoptosis and inhibition of cell proliferation during the pathogenesis of Habu nephritis after unilateral nephrectomy [35-37]. This study focused on the role of VIL1 in the HabuU model. VIL1 was reported [27] to be expressed predominantly in proximal tubular cells, whereas few studies have evaluated its expression in mesangial cells. In this study, we found VIL1 expression was abundant in glomeruli and mesangial cells (Fig. 7). VIL1 is closely related to cell growth and apoptosis [33], and thus its downregulation may be involved in mesangial proliferation inhibition and cell apoptosis during Habu nephritis after unilateral nephrectomy. We demonstrated that

Table 1. The DEPs listed in Fig. 5. (-) The DEP was not detected at both days. $7 \mathrm{~d}^{\#}$ or $14 \mathrm{~d}^{\#}$, the DEP was detected at day 7 or 14 , but not at day 0

\begin{tabular}{|c|c|c|c|c|c|}
\hline \multirow{3}{*}{ Protein Accession } & \multirow{3}{*}{ Protein Name } & \multicolumn{4}{|c|}{ Fold } \\
\hline & & \multicolumn{2}{|c|}{ Habu Model } & \multicolumn{2}{|c|}{ HabuU Model } \\
\hline & & $7 d / 0 d$ & $14 \mathrm{~d} / 0 \mathrm{~d}$ & $7 \mathrm{~d} / 0 \mathrm{~d}$ & $14 \mathrm{~d} / 0 \mathrm{~d}$ \\
\hline NP_570934.1 & Acaa1a & 0,77 & 0,59 & 1,26 & 1,03 \\
\hline NP_666342.1 & Acaa1b & 0,78 & 0,63 & 1,01 & 0,79 \\
\hline NP_031408.1 & Acadm & 0,51 & 0,36 & 0,89 & 0,68 \\
\hline NP_031409.2 & Acads & 0,53 & 0,27 & 1,52 & 1,30 \\
\hline NP_659033.1 & Acat1 & 0,44 & 0,37 & 0,83 & 0,66 \\
\hline NP_033364.2 & Acat2 & 0,43 & 0,35 & $7 d^{\#}$ & $14 d^{\#}$ \\
\hline NP_031412.2 & Aco1 & 0,81 & 0,83 & 0,64 & 0,79 \\
\hline NP_598917.1 & Actn1 & 1,34 & 1,27 & 0,36 & 0,77 \\
\hline NP_150371.4 & Actn2 & 1,43 & 1,40 & 0,41 & 0,73 \\
\hline NP_038484.1 & Actn3 & 1,38 & 1,43 & 0,29 & 0,66 \\
\hline NP_068695.1 & Actn4 & 1,27 & 1,25 & 0,28 & 0,62 \\
\hline NP_067448.1 & Akr1a4 & 0,49 & 0,39 & 1,46 & 1,38 \\
\hline NP_659152.1 & Aldob & 0,52 & 0,34 & 1,86 & 1,16 \\
\hline NP_033787.2 & Aldoc & 1,00 & 0,95 & 0,55 & 0,70 \\
\hline NP_034063.1 & Col6a1 & 0,82 & 0,83 & 0,30 & 1,39 \\
\hline NP_080720.1 & Cs & 0,48 & 0,39 & 1,48 & 1,57 \\
\hline NP_082221.2 & Csl & 0,76 & 0,54 & 1,25 & 1,40 \\
\hline NP_031887.2 & Dld & 1,30 & 1,97 & 1,06 & 1,95 \\
\hline NP_076226.2 & Ehhadh & 2,39 & 5,00 & 0,62 & 0,90 \\
\hline NP_075608.2 & Eno1 & 1,02 & 0,57 & 2,69 & 2,64 \\
\hline NP_038537.1 & Eno2 & 1,03 & 0,57 & 2,66 & 2,51 \\
\hline NP_031959.1 & Eno3 & 1,04 & 0,58 & 2,69 & 2,51 \\
\hline NP_062268.1 & Fbp 1 & 0,50 & 0,36 & 1,45 & 1,55 \\
\hline NP_034339.2 & Fh1 & 0,39 & 0,16 & 1,32 & 1,30 \\
\hline NP_034342.1 & Fhl2 & 2,80 & 2,94 & 1,77 & 1,86 \\
\hline NP_666232.2 & Gsn & 2,29 & 3,03 & 0,84 & 2,10 \\
\hline NP_849209.1 & Hadha & 1,73 & 2,61 & 0,43 & 0,83 \\
\hline NP_663533.1 & Hadhb & 1,75 & 1,70 & 0,73 & 0,80 \\
\hline NP_666220.1 & Hibch & 0,48 & 0,40 & 1,28 & 1,51 \\
\hline NP_001139572.1 & Hk1 & 1,42 & 2,12 & 0,54 & 1,21 \\
\hline NP_001104790.1 & Idh1 & 0,43 & 0,30 & 1,55 & 1,32 \\
\hline NP_766599.2 & Idh2 & 0,49 & 0,36 & 1,40 & 1,52 \\
\hline NP_083849.1 & Idh3a & 0,60 & 0,40 & 1,02 & 1,08 \\
\hline NP_570954.1 & Idh3b & 0,66 & 0,39 & 1,80 & 1,80 \\
\hline NP_032349.1 & $\operatorname{Idh} 3 g$ & 0,52 & 0,42 & 1,14 & 1,03 \\
\hline NP_038593.1 & $\operatorname{Itga} 3$ & 2,08 & 2,53 & 0,60 & 2,05 \\
\hline NP_032423.2 & Itga6 & 1,32 & 1,99 & 0,45 & 1,51 \\
\hline NP_001001309.1 & Itga8 & $(-)$ & $(-)$ & $(-)$ & $14 d^{\#}$ \\
\hline NP_034708.1 & Itgb1 & 1,99 & 2,39 & 0,61 & 2,05 \\
\hline NP_034710.2 & Itgb5 & $(-)$ & $(-)$ & $(-)$ & $14 d^{\#}$ \\
\hline NP_062800.1 & Ivd & 0,52 & 0,49 & 1,97 & 1,58 \\
\hline NP_001129541.2 & Ldha & $7 \mathrm{~d}^{\#}$ & $(-)$ & $(-)$ & $(-)$ \\
\hline NP_038608.1 & Ldhc & $(-)$ & $14 d^{\#}$ & $(-)$ & $(-)$ \\
\hline NP_032676.2 & Mut & 1,17 & 1,31 & 0,46 & 0,76 \\
\hline NP_542369.2 & Mvp & 1,00 & 1,14 & 0,88 & 2,20 \\
\hline NP_780469.1 & Myh10 & 1,40 & 0,94 & 1,26 & 2,05 \\
\hline NP_071855.2 & Myh9 & 1,48 & 1,02 & 1,46 & 2,01 \\
\hline NP_077150.1 & Oxct1 & 2,23 & 3,32 & 1,12 & 2,41 \\
\hline NP_001156418.1 & $\mathrm{Pc}$ & 1,09 & 1,32 & 0,38 & 0,68 \\
\hline NP_032836.1 & Pdha1 & 0,45 & 0,30 & 1,26 & 1,22 \\
\hline NP_075907.2 & Pgam1 & 0,98 & 0,37 & 1,21 & 1,12 \\
\hline NP_032854.2 & Pgk1 & 0,44 & 0,25 & 1,32 & 1,02 \\
\hline NP_035229.2 & Pkm2 & 1,63 & 2,25 & $7 d^{\#}$ & $14 d^{\#}$ \\
\hline NP_001098086.1 & $\mathrm{Rdx}$ & 1,49 & 2,77 & 0,53 & 0,97 \\
\hline NP_035021.1 & Sept2 & $7 \mathrm{~d}^{\#}$ & $14 d^{\#}$ & 1,82 & 2,32 \\
\hline NP_033528.3 & $\mathrm{Vcl}$ & 2,83 & 3,29 & 0,62 & 1,46 \\
\hline NP_033535.2 & Vil1 & 1,07 & 1,01 & 0,41 & 0,44 \\
\hline
\end{tabular}
proliferation and promoted apoptosis by increasing the expression of p21, p27, Bax, and caspase 3. p21 and p27 are negative regulators of cell growth, and their activation promotes cell arrest and apoptosis. Moreover, Bax and p21 activate caspase 3 to induce apoptosis [38]. VIL1 has an F-actin-binding site in its headpiece domain, which can bind and sever F-actin [23], and downregulation of VIL1 may regulate these proteins via interaction with F-actin [37, 39], which in turn affects the p53, ERK and AKT signaling pathways [40-42]. These signaling pathways may influence cell proliferation and apoptosis by regulating the production of cell cycle regulatory proteins and apoptotic proteins. Therefore, downregulation of VIL1 may play a crucial role in Habu nephritis after unilateral nephrectomy by inhibiting the recovery of mesangiolysis via interfering with cell proliferation and promoting apoptosis. 


\section{Cellular Physiology Cell Physiol Biochem 2016;39:1761-1776 \begin{tabular}{ll|l} 
DOI: 10.1159/000447876 & (O 2016 The Author(s). Published by S. Karger AG, Basel
\end{tabular}

Fig. 6. The effect of VIL1 downregulation on MMC proliferation and apoptosis. (A) Validation of VIL1, FHL2 and SEPT2 levels in glomeruli by Western blotting. (B) Cell counts. Data are expressed as fold changes compared with the $\mathrm{NC}$ group, which was normalized to 1 (mean \pm SD). (C) Hoechst staining to detect MMC apoptosis. The percentage of cells with condensed nuclei among the total number of cells represents the degree of apoptosis (mean \pm SD). (D) EdU incorporation assay of MMC proliferation (red, EDU; blue, DAPI; pink, merged). The percentage of EDU-positive cells among the total number of cells represents the degree of proliferation (mean \pm SD). (E)VIL1, caspase 3, p 21, p27 and Bax expression levels were determined by Western blotting. The intensities of the protein bands are presented as ratios to those of the $\beta$-actin bands; data from the NC group were arbitrarily set as 1.0 . ${ }^{*}$ Significant difference $(p<0.05)$ compared with the NC group. ${ }^{* *}$ Predominant significant difference $(p<0.01)$ compared with the NC group. All experiments were performed in at least triplicate.

\section{Conclusion}

In conclusion, persistent mesangiolysis with focal hypercellularity in the HabuU model at days 7 and 14 contributed to more serious renal function damage compared with the Habu model. Bioinformatics analysis showed that specific DEPs mediated various biological functions-including aberrant energy metabolism, regulation of actin cytoskeleton, and focal adhesion - which may be associated with pathological lesions in the HabuU model. Moreover, downregulation of VIL1 may be involved in glomerular self-repair inefficiency in

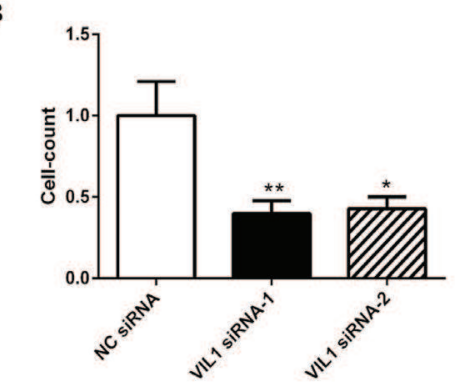

C
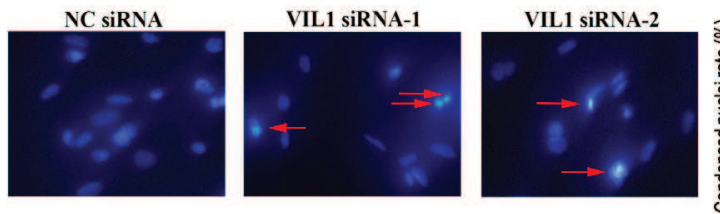

D NC SiRNA

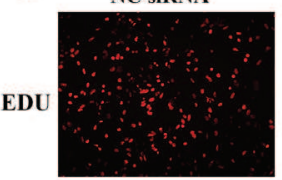

VIL1 siRNA-1
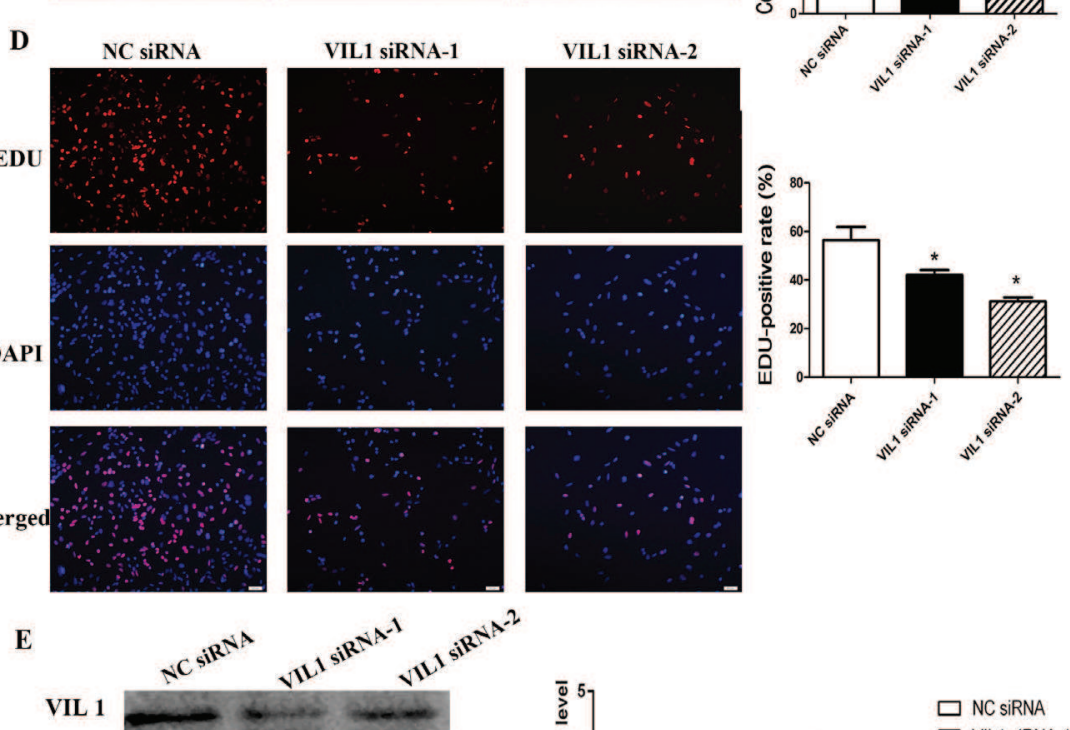

Caspase 3

Bax

p21

p27

$\beta$-actin

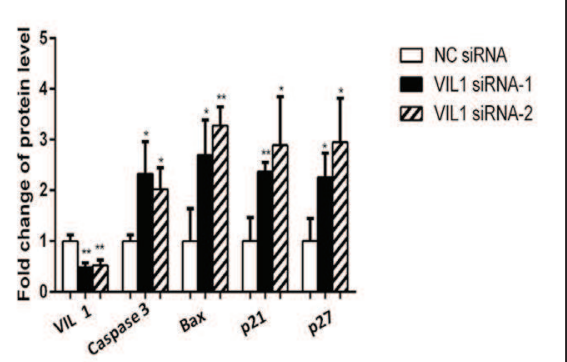




\section{Cellular Physiology Cell Physiol Biochem 2016;39:1761-1776 \begin{tabular}{l|l|l} 
DOI: 10.1159/000447876 & ( ) 2016 The Author(s). Published by S. Karger AG, Basel
\end{tabular} \\ Chen et al.: Proteomics Analysis of Habu Nephritis with Versus without UNX}

A

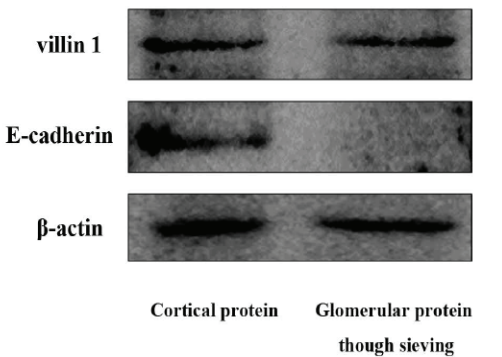

B

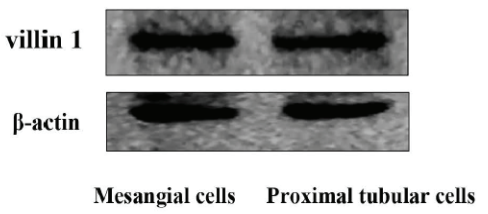

Fig. 7. VIL1 and E-cadherin expression as determined by Western blotting. (A) VIL1 and E-cadherin expression in cortical and glomerular protein. (B) VIL1 expression in human mesangial cells and proximal tubular cells.

A

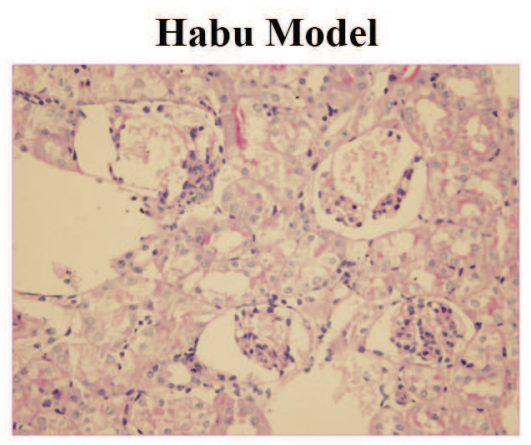

B

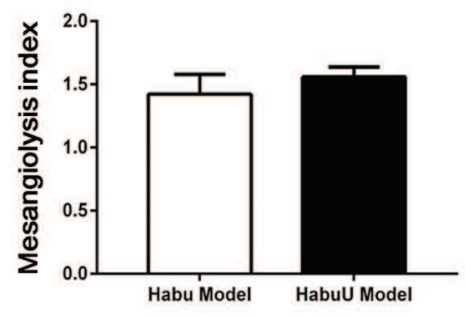

\section{HabuU Model}
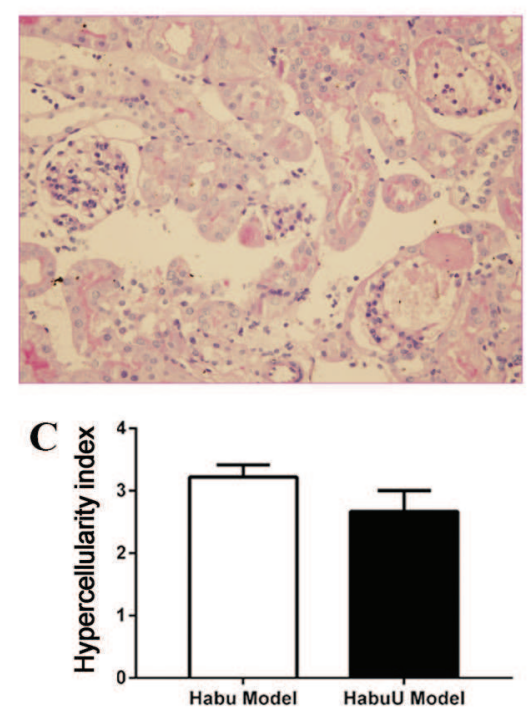

Fig. 8. Histological features of the two models at day 1 in the pre-experiment. (A) Periodic acid-Schiff (PAS) staining of renal tissues obtained at day 1 after HSV injection in the two models. (B) The mesangiolysis index of renal tissues obtained at day 1 in the two models ( $n=3$ per group and at least 30 glomeruli per mouse; $1.42 \pm 0.16$ vs. $1.55 \pm 0.08$, Habu model vs. HabuU model, $\mathrm{p}=0.274$ ). (C) The hypercellularity index of renal tissues obtained at day 1 in the two models ( $n=3$ per group and at least 30 glomeruli per mouse; $0.32 \pm 0.020$ vs. $0.27 \pm 0.33$, Habu model vs HabuU model, $p=0.068$ ).

the HabuU model by inhibiting cell proliferation and promoting apoptosis, which provides insight into the specific mechanism underlying the progression of Habu nephritis after unilateral nephrectomy. These findings suggest novel targets for the diagnosis and therapy of kidney disease, particularly for patients with a single kidney.

\section{Abbreviations}

HSV (Habu Snake Venom); UNX (unilateral nephrectomy); HabuU model (Habu model with unilateral nephrectomy); DEPs (differentially expressed proteins); MMCs (mouse mesangial cell); DN (diabetic nephropathy); AKI (acute kidney injury); GS (glomerular sclerosis); MesGN (mesangial proliferative glomerulonephritis); PAS (periodic acid-Schiff); 


\section{Cellular Physiology Cell Physiol Biochem 2016;39:1761-1776 \begin{tabular}{l|l|l|l}
$: 10.1159 / 000447876$ & () 2016 The Author(s). Published by S. Karger AG, Basel
\end{tabular} and Biochemistry Published online: October 17, 2016 www.karger.com/cpb

PCNA (proliferating cell nuclear antigen); VIL1 (villin1); KEGG (Kyoto Encyclopedia of Genes and Genomes).

\section{Acknowledgments}

This work was supported by the Beijing Nova Program (nos. xx2014B096), the National Natural Science Foundation of China (nos. 81330019 and 81270794), and the National Basic Research Program of China (nos. 2013CB530800 and 2014CBA02005).

\section{Disclosure Statement}

The authors declare that they have no competing interests.

\section{References}

1 Blantz RC, Steiner RW: Benign hyperfiltration after living kidney donation. J Clin Invest 2015;125:972-974.

2 Chen Z, Fang J, Li G, Zhang L, Xu L, Pan G, Ma J, Qi H: Compensatory changes in the retained kidney after nephrectomy in a living related donor. Transplant Proc 2012;44:2901-2905.

3 Wormser C, Aronson LR: Perioperative morbidity and long-term outcome of unilateral nephrectomy in feline kidney donors: 141 cases (1998-2013). J Am Vet Med Assoc 2016;248:275-281.

4 Rayner HC, Ward L, Walls J: Cholesterol feeding following unilateral nephrectomy in the rat leads to glomerular hypertrophy. Nephron 1991;57:453-459.

5 Chagnac A, Korzets A, Ben-Bassat M, Zevin D, Hirsh J, Meckler J, Levi J: Uninephrectomy aggravates tubulointerstitial injury in rats with adriamycin nephrosis. Nephron 1994;66:176-180.

6 Zheng S, Huang Y, Yang L, Chen T, Xu J, Epstein PN: Uninephrectomy of diabetic OVE26 mice greatly accelerates albuminuria, fibrosis, inflammatory cell infiltration and changes in gene expression. Nephron Exp Nephrol 2011;119:e21-32.

7 Katsuda Y, Kemmochi Y, Maki M, Sano R, Toriniwa Y, Ishii Y, Miyajima K, Kakimoto K, Ohta T: Effects of unilateral nephrectomy on renal function in male Spontaneously Diabetic Torii fatty rats: a novel obese type 2 diabetic model. J Diabetes Res 2014;2014:363126-363126.

8 Ma LJ, Jha S, Ling H, Pozzi A, Ledbetter S, Fogo AB: Divergent effects of low versus high dose anti-TGF-beta antibody in puromycin aminonucleoside nephropathy in rats. Kidney Int 2004;65:106-115.

9 Wada Y, Morioka T, Oyanagi-Tanaka Y, Yao J, Suzuki Y, Gejyo F, Arakawa M, Oite T: Impairment of vascular regeneration precedes progressive glomerulosclerosis in anti-Thy 1 glomerulonephritis. Kidney Int 2002;61:432-443.

10 Wang B, Ding W, Zhang M, Li H, Gu Y: Rapamycin attenuates aldosterone-induced tubulointerstitial inflammation and fibrosis. Cell Physiol Biochem 2015;35:116-125.

11 Xia M, Conley SM, Li G, Li PL, Boini KM: Inhibition of hyperhomocysteinemia-induced inflammasome activation and glomerular sclerosis by NLRP3 gene deletion. Cell Physiol Biochem 2014;34:829-841.

12 Liang Y, Zhang J, Zhou Y, Xing G, Zhao G, Liu Z: Proliferation and cytokine production of human mesangial cells stimulated by secretory IgA isolated from patients with IgA nephropathy. Cell Physiol Biochem 2015;36:1793-1808.

13 Yu M, Song Y, Zhu MX, Liang W, Long Q Ding PW, Xie Y, Liao YH, Yuan J: B10 cells ameliorate the progression of lupus nephritis by attenuating glomerular endothelial cell injury. Cell Physiol Biochem 2015;36:21612169.

14 Dimmler AHaas CS, Cho S, Hattler M, Forster C, Peters H, Schocklmann HO, Amann K: Laser capture microdissection and real-time PCR for analysis of glomerular endothelin-1 gene expression in mesangiolysis of rat anti-Thy 1.1 and murine Habu Snake Venom glomerulonephritis. Diagn Mol Pathol 2003;12:108-117. 


\section{Cellular Physiology Cell Physiol Biochem 2016;39:1761-1776 \begin{tabular}{l|l|l|l}
\cline { 2 - 3 } DOI: 10.1159/000447876 & () 2016 The Author(s). Published by S. Karger AG, Basel
\end{tabular} and Biochemistry Published online: October 17, 2016 www.karger.com/cpb}

Chen et al.: Proteomics Analysis of Habu Nephritis with Versus without UNX

15 Ishizaki M, Masuda Y, Fukuda Y, Sugisaki Y, Yamanaka N, Masugi Y: Experimental mesangioproliferative glomerulonephritis in rats induced by intravenous administration of anti-thymocyte serum. Pathol Int 1986;36:1191-1203.

16 Hartner A, Marek I, Cordasic N, Haas C, Schocklmann H, Hulsmannvolkert G, Plasa I, Rascher W, Hilgers KF, Amann K: Glomerular regeneration is delayed in nephritic $\alpha 8$-integrin-deficient mice: contribution of $\alpha 8$ integrin to the regulation of mesangial cell apoptosis. Am J Nephrol 2008;28:168-178.

17 Haas CS, Câmpean V, Kuhlmann A, Dimmler A, Reulbach U, Forster C, Aigner T, Acker T, Plate K, Amann $\mathrm{K}$ : Analysis of glomerular VEGF mRNA and protein expression in murine mesangioproliferative glomerulonephritis. Virchows Arch Pathol Anat Physiol Klin Med 2007;450:81-92.

18 Tsuji M, Monkawa T, Yoshino J, Asai M, Fukuda S, Kawachi H, Shimizu F, Hayashi M, Saruta T: Microarray analysis of a reversible model and an irreversible model of anti-Thy-1 nephritis. Kidney Int 2006;69:9961004.

19 Jiang L, Liu G, Jicheng LV, Huang C, Chen BO, Wang S, Zou W, Zhang H, Wang H: Concise semiquantitative histological scoring system for immunoglobulin A nephropathy. Nephrology 2009;14:597-605.

20 Lu Y, Cai G, Cui S, Geng W, Chen D, Wen J, Zhang Y, Zhang F, Xie Y, Fu B, Chen X: FHL2-driven molecular network mediated Septin2 knockdown inducing apoptosis in mesangial cell. Proteomics 2014;14:24852497.

21 Shen Z, Li P, Ni RJ, Ritchie M, Yang CP, Liu GF, Ma W, Liu GJ, Ma L, Li SJ, Wei ZG, Wang HX, Wang BC: Label-free quantitative proteomics analysis of etiolated maize seedling leaves during greening. Mol Cell Proteomics 2009;8:2443-2460.

22 Xu D, Suenaga N, Edelmann MJ, Fridman R, Muschel RJ, Kessler BM: Novel MMP-9 substrates in cancer cells revealed by a label-free quantitative proteomics approach. Mol Cell Proteomics 2008;7:2215-2228.

23 Bretscher A, Weber K: Villin is a major protein of the microvillus cytoskeleton which binds both G and F actin in a calcium-dependent manner. Cell 1980;20:839-847.

24 Phillips MJ, Azuma T, Meredith SL, Squire JA, Ackerley CA, Pluthero FG, Roberts EA, Superina RA, Levy GA, Marsden PA: Abnormalities in villin gene expression and canalicular microvillus structure in progressive cholestatic liver disease of childhood. Lancet 2003;362:1112-1119.

25 Khurana S: Structure and function of Villin; in Bittar EE, Pusch M (eds): Advances in Molecular and Cell Biology, Elsevier, 2006, vol 37, pp 89-117.

26 Wang Y, Srinivasan K, George S, Tomar A, Khurana S: A novel role for Villin in intestinal epithelial cell survival and homeostasis. J Biol Chem 2008;283:9454-9464.

27 Pringault E, Arpin M, Garcia A, Finidori J, Louvard D: A human villin cDNA clone to investigate the differentiation of intestinal and kidney cells in vivo and in culture. EMBO J 1987;5:3119-3124.

28 Barnes JL, Abboud HE: Temporal expression of autocrine growth factors corresponds to morphological features of mesangial proliferation in Habu snake venom-induced glomerulonephritis. Am J Pathol 1993;143:1366-1376.

29 Abe-Yoshio Y, Abe K, Miyazaki M, Furusu A, Nishino T, Harada T, Koji T, Kohno S: Involvement of bone marrow-derived endothelial progenitor cells in glomerular capillary repair in habu snake venom-induced glomerulonephritis. Virchows Arch 2008;453:97-106.

30 Baker AJ, Mooney A, Hughes J, Lombardi D, Johnson RJ, Savill J: Mesangial cell apoptosis: the major mechanism for resolution of glomerular hypercellularity in experimental mesangial proliferative nephritis. J Clin Invest 1994;94:2105-2116.

31 Yoshimura A, Gordon K, Alpers CE, Floege J, Pritzl P, Ross R, Couser WG, Bowen-Pope DF, Johnson RJ: Demonstration of PDGF B-chain mRNA in glomeruli in mesangial proliferative nephritis by in situ hybridization. Kidney Int 1991;40:470-476.

32 Morita T, Yamamoto T, Churg J: Mesangiolysis: An update - American Journal of Kidney Diseases. Am J Kidney Dis 1998;31:559-573.

33 Agathocleous M, Harris WA: Metabolism in physiological cell proliferation and differentiation. Trends Cell Biol 2013;23:484-492.

34 Deberardinis RJ, Lum JJ, Hatzivassiliou G, Thompson CB: The biology of cancer: metabolic reprogramming fuels cell growth and proliferation. Cell Metab 2008;7:11-20.

35 Fletcher GC, Ahmed E, Ichha K, Ribeiro PS, Nic T, Thompson BJ: The Spectrin cytoskeleton regulates the Hippo signalling pathway. EMBO J 2015;34:940-954.

36 Rakesh K, Gururaj AE, Barnes CJ: p21-activated kinases in cancer. Nat Rev Cancer 2006;6:459-471. 
37 Wang, YH, George, Srinivasan, Siddiqui, Mathew: Reorganization of cytoskeleton as basis for apoptosis. Gastroenterology 2008;134:A-70.

38 Noguchi K, Kato K, Yang G, Suzuki T, Kubota Y, Dairaku N, Oikawa K, Konno Y, Sekine H, Ohara S: P21, Bax and Caspase 3 participate in the propagating mechanism of apoptosis in the human gastric epithelial cells. Gastroenterology 2000;118:A1404.

39 Jianmin M, Didem V, Yeming W, Hwai-Chen G, Head JF, C James M: High-resolution crystal structures of villin headpiece and mutants with reduced F-actin binding activity. Biochemistry 2005;44:11963-11973.

40 Okorokov AL, Rubbi CP, Su M, Jo M: The interaction of p53 with the nuclear matrix is mediated by F-actin and modulated by DNA damage. Oncogene 2002;21:356-367.

41 Heijden MVD, Versteilen AMG, Sipkema P, Amerongen GPVN, Musters RJP, Groeneveld ABJ: Rho-kinasedependent F-actin rearrangement is involved in the inhibition of PI3-kinase/Akt during ischemiareperfusion-induced endothelial cell apoptosis. Apoptosis 2008;13:404-412.

42 Zhi-Gang C, Jia-Ping Z, Hua-Pei S, Jiong-Yu H, Qiong Z, Fei X, Yue-Sheng H: p38 MAP kinase mediates burn serum-induced endothelial barrier dysfunction: involvement of F-actin rearrangement and L-caldesmon phosphorylation. Shock 2010;34:222-228. 